\section{References}

1. Fisher JN, Thanasopoulou A, Juge S. et al.Transforming activities of the NUP98-KMT2A fusion gene associated with myelodysplasia and acute myeloid leukemia. Haematologica 2020;105(7):1857-1867.

2. Kaltenbach S, Soler G, Barin C, et al. NUP98-MLL fusion in human acute myeloblastic leukemia. Blood. 2010;116(13):2332-2335.

3. Li BE, Ernst P. Two decades of leukemia oncoprotein epistasis: the MLL1 paradigm for epigenetic deregulation in leukemia. Exp Hematol. 2014;42(12):995-1012.

4. Slany RK. MLL fusion proteins and transcriptional control. Biochim Biophys Acta Gene Regul Mech. 2020;1863(3):194503.

5. Yokoyama A, Somervaille TCP, Smith KS, Rozenblatt-Rosen O, Meyerson M, Cleary ML. The menin tumor suppressor protein is an essential oncogenic cofactor for MLL-associated leukemogenesis. Cell. 2005;123(2):207-218.

6. Gilan O, Lam EYN, Becher I, et al. Functional interdependence of BRD4 and DOT1L in MLL leukemia. Nat Struct Mol Biol. 2016;23(7):673-681.

7. Daigle SR, Olhava EJ, Therkelsen CA, et al. Selective killing of mixed lineage leukemia cells by a potent small-molecule DOT1L inhibitor. Cancer Cell. 2011;20(1):53-65.

8. Krivtsov AV, Evans K, Gadrey JY, et al. A menin-MLL inhibitor induces specific chromatin changes and eradicates disease in models of MLL-rearranged leukemia. Cancer Cell. 2019;36(6):660-673.e11.

9. Gaussmann A, Wenger T, Eberle I, et al. Combined effects of the two reciprocal $\mathrm{t}(4 ; 11)$ fusion proteins MLL.AF4 and AF4.MLL confer resistance to apoptosis, cell cycling capacity and growth transformation. Oncogene. 2007;26(23):3352-3363.

10. Zhang Y, Yan X, Sashida G, et al. Stress hematopoiesis reveals abnormal control of self-renewal, lineage bias, and myeloid differentiation in Mll partial tandem duplication (Mll-PTD) hematopoietic stem/progenitor cells. Blood. 2012;120(5):1118-1129.

11. Sun Q-Y, Ding L-W, Tan K-T, et al. Ordering of mutations in acute myeloid leukemia with partial tandem duplication of MLL (MLLPTD). Leukemia 2017;31(1):1-10.

12. Jeganathan KB, Malureanu L, van Deursen JM. The Rae1-Nup98 complex prevents aneuploidy by inhibiting securin degradation. Nature. 2005;438(7070):1036-1039.

13. Kalverda B, Pickersgill H, Shloma VV, Fornerod M. Nucleoporins directly stimulate expression of developmental and cell-cycle genes inside the nucleoplasm. Cell. 2010;140(3):360-371.

14. Pascual-Garcia P, Jeong J, Capelson M. Nucleoporin Nup98 associates with Trx/MLL and NSL histone-modifying complexes and regulates Hox gene expression. Cell Rep. 2014;9(5):1981.

15. Struski S, Lagarde S, Bories P, et al. NUP98 is rearranged in $3.8 \%$ of pediatric AML forming a clinical and molecular homogenous group with a poor prognosis. Leukemia. 2017;31(3):565-572.

16. Gough SM, Slape CI, Aplan PD. NUP98 gene fusions and hematopoietic malignancies: common themes and new biologic insights. Blood. 2011;118(24):6247-6257.

17. $\mathrm{Xu} \mathrm{H}$, Valerio DG, Eisold ME, et al. NUP98 fusion proteins interact with the NSL and MLL1 complexes to drive leukemogenesis. Cancer Cell. 2016;30(6):863-878.

18. Thanasopoulou A Tzankov A Schwaller I. Potent co-operation between the NUP98-NSD1 fusion and the FLT3-ITD mutation in acute myeloid leukemia induction. Haematologica. 2014;99(9):1465 1471.

19. Stavropoulou V, Kaspar S, Brault L, et al. MLL-AF9 Expression in Hematopoietic stem cells drives a highly invasive AML expressing EMT-related genes linked to poor outcome. Cancer Cell. 2016;30(1):43-58

20. So CW, Lin M, Ayton PM, Chen EH, Cleary ML. Dimerization contributes to oncogenic activation of MLL chimeras in acute leukemias. Cancer Cell. 2003;4(2):99-110.

21. Vedadi M, Blazer L, Eram MS, Barsyte-Lovejoy D, Arrowsmith CH, Hajian T. Targeting human SET1/MLL family of proteins. Protein Sci. 2017;26(4):662-676.

\title{
T-cell and NK-cell neoplasms of the gastrointestinal tract - recurrent themes, but clinical and biological distinctions exist
}

\author{
Elaine S. Jaffe
}

Hematopathology Section, Laboratory of Pathology, Center for Cancer Research, National Cancer Institute, National Institutes of Health, Bethesda, MD, USA.

E-mail: ELAINE S. JAFFE - ejaffe@mail.nih.gov

doi:10.3324/haematol.2020.252924

$\mathrm{T}$ he history of intestinal T-cell lymphomas begins with the early work of Peter Isaacson and Dennis Wright who described cases of "malignant histiocytosis" of the intestine that they linked to malabsorption and ulcerative jejunitis. ${ }^{1}$ Subsequent work showed that "malignant histiocytosis of the intestine" was a form of Tcell lymphoma, later named enteropathy-associated $\mathrm{T}$ cell lymphoma (EATL). ${ }^{2}$ Since then, we have come to understand the distinction between EATL, closely linked to celiac disease, and monomorphic epitheliotropic T-cell lymphoma (MEITL), formerly EATL type II (Figure 1). ${ }^{3}$ The work of Isaacson and Wright shaped the modern classification of both T-cell and B-cell intestinal lymphomas, giving us not only EATL, but also mucosa-associated lymphoid tissue (MALT) lymphoma. Sadly Dennis Wright passed away on April 08, 2020 at the age of 88.

Most cases of intestinal T-cell lymphoma were highly aggressive, but in the 1990s there was a series of reports of low-grade intestinal T-cell neoplasms, some of which mimicked lymphomatous polyposis. ${ }^{48}$ The nature of this rare form of T-cell lymphoma was better defined in sub- sequent reports, ${ }^{9,10}$ and incorporated into the Revised $4^{\text {th }}$ Edition of the World Health Organization (WHO) classification $^{3}$ as a provisional entity under the term indolent $\mathrm{T}$ cell lymphoproliferative disorder of the gastrointestinal tract (ITLPD-GIT) (Figure 1). Most patients had a chronic, relapsing clinical course, although in both of the above series late instances of large-cell transformation were described. ${ }^{10,11}$

In the current issue of Haematologica, Soderquist et al. expand our knowledge regarding the immunophenotypic spectrum of ITLPD-GIT and provide new insights into its molecular pathogenesis. ${ }^{12}$ As with prior reports, all cases were derived from $\alpha \beta \mathrm{T}$ cells with an equal proportion of cases expressing either CD4 or CD8. One case each had either a double-positive or double-negative phenotype. The authors also examined the expression of T-bet (TBX21) and GATA3, but any conclusions regarding the functional or clinical significance of these markers, which have been examined more extensively in nodal peripheral T-cell lymphomas,$^{13}$ remain premature.

This study confirms the importance of alterations in 
JAK-STAT pathway genes in cases of ITLPD-GIT with a $\mathrm{CD}_{4}+$ phenotype. Five of six cases, either $\mathrm{CD} 4^{+}$, or double-negative in one instance, had alterations with predicted activation of the pathway. Interestingly, functional evidence of activation of the pathway was less convincing. Cells with nuclear staining for p-STAT3 and p-STAT5 accounted for fewer than $10 \%$ of total cells in all nine cases studied. Activation of the JAK-STAT pathway is a very common finding in many forms of T-cell lymphoma, most of which have a cytotoxic phenotype. Initially reported in T-cell large granular lymphocyte leukemia, ${ }^{14}$ activation of this pathway is a regular feature of hepatosplenic T-cell lymphoma, ${ }_{15}^{15}$ intestinal T-cell lymphomas, ${ }^{16,17}$ anaplastic large cell lymphoma (ALCL), ALKpositive and ALK-negative, ${ }^{18,19}$ and breast-implant-associated ALCL. ${ }^{20,21}$ Interestingly, similar alterations were not seen in the $\mathrm{CD}^{+}$cases, which share a cytotoxic phenotype with many of the above mentioned lesions. However, JAK3 mutations have been reported in NK-cell enteropathy, an indolent NK-cell derived lymphoprolifer- ative disease of the gastrointestinal tract that has a chronic relapsing and remitting clinical course similar to that of ITLPD-GIT. ${ }^{22}$

Prior reports have noted that ITLPD-GIT with a CD8 ${ }^{+}$ phenotype has a similar immunophenotypic profile to that of primary cutaneous acral CD8 ${ }^{+} \mathrm{T}$-cell lymphoma, another newly recognized provisional entity in the revised WHO classification. ${ }^{3}$ This tumor presents with superficial, non-epidermotropic cutaneous lesions. Initially reported on the ear, it has subsequently been recognized presenting in other acral cutaneous sites. The neoplastic cells have a cytotoxic T-cell phenotype but, as in ITLPD-GIT, are positive for TIA-1 although negative for granzyme B and perforin. Acral CD8 ${ }^{+}$T-cell lymphoma has a similar indolent clinical course as ITLPDGIT, with a low risk of disease beyond the skin. Given the current report by Soderquist et al., which describes structural alterations of the IL2 gene, extending these studies to other forms of indolent T-cell lymphoma is warranted. It is also notable both in this study, and in

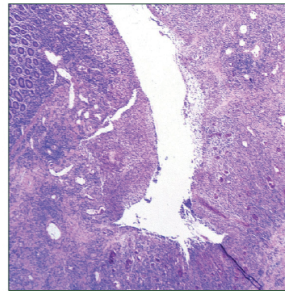

EATL

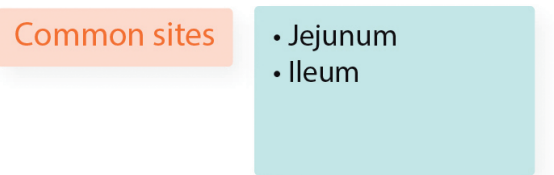

$\begin{array}{ll}\text { Phenotype } & \cdot a \beta>\gamma \delta \\ \cdot C D 3+/ C D 5- \\ \cdot C D 103+ \\ \cdot C D 4-/ C D 8-\end{array}$

Genotype
Clinical

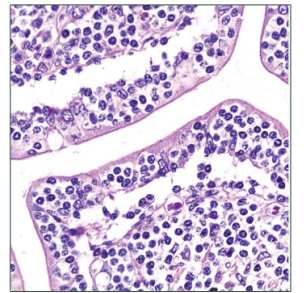

MEITL

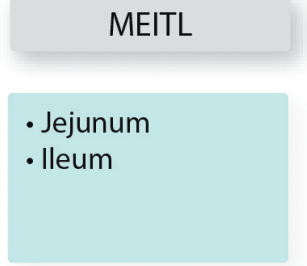

\section{- $\gamma \delta>a \beta$ \\ - CD3+/CD5- \\ - CD8-/CD56+ \\ - MATK}

- JAK-STAT

- STAT5B/JAK3

- SETD2

- RAS pathway

- No predisposing
factors
- All ethnic groups
- Aggressive

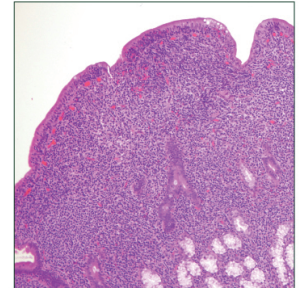

IT-LPD

- Duodenum
- Jejunum
- lleum
- Colon

- $\alpha \beta$

- CD3+/CD5+ - CD4 or CD8

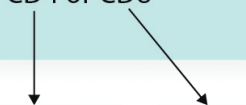

JAK-STAT - IL2 R/D

- RAS

- Epigenetic modifiers

\section{- Indolent - Slight risk of transformation - $\mathrm{CD} 4>\mathrm{CD} 8$}

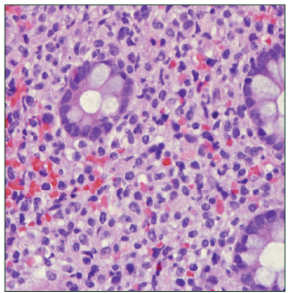

NK-ENT

\section{- Stomach \\ - Duodenum \\ - SB, Colon}

- Neg $\gamma \delta-a \beta$

- cCD3+/CD5-

- $\mathrm{CD} 7+$

$\cdot \mathrm{CD} 56+$

\section{- JAK-STAT}

- JAK3

- Indolent

- No transformation

reported

Figure 1. Distinguishing features of primary intestinal T-cell and NK-cell neoplasms. Major biological and clinical features of enteropathy-associated T-cell lymphoma (EATL), monomorphic epitheliotropic T-cell lymphoma (MEITL), indolent T-cell lymphoproliferative disorder of the gastrointestinal tract (IT-LPD) and natural killer-cell enteropathy (NK-ENT) are shown. EATL and MEITL are clinically aggressive, whereas IT-LPD and NK-ENT have a chronic relapsing clinical course, with a low risk of dissemination or transformation. Common recurrent features include a cytotoxic phenotype and activation of the JAK-STAT pathway in most of the entities. EATL: enteropathy associated T-cell lymphoma; MEITL: monomorphic epitheliotropic intestinal T-cell lymphoma; IT-LPD, indolent T-cell lymphoproliferative disorder of the gastrointestinal tract; NK-ENT, natural killer-cell enteropathy; SB; small bowel; R/D, rearrangement or deletion. 
prior work, that the molecular pathogenesis of the CD4 and $\mathrm{CD}^{+}$cases of ITLPD-GIT appears distinct. ${ }^{10,23}$ Thus, more formal separation of these phenotypic variants may be warranted in the future.

The current series presents both similarities with and differences from prior clinical reports. ${ }^{12}$ Endoscopic findings included multiple mucosal lesions, often with nodularity or polyps. Only one case was associated with mucosal ulceration. Most of the patients had a very protracted clinical course, with two patients being alive 19 and 21 years after diagnosis. There is a small but significant risk of transformation, with disease progressing in two patients after 11 and 27 years of follow-up. A variety of treatments were employed, with no patient stated to attain a complete remission.

In prior series, all patients had disease confined to the gastrointestinal tract, with extraintestinal dissemination seen only in patients with histological progression., ${ }^{9,10}$ However, Soderquist et al. report bone marrow involvement in three cases, all of which were detected prior to transformation. In one case bone marrow involvement was detected only through an unidentified cytogenetic abnormality; the bone marrow was morphologically normal and lacked evidence of a monoclonal T-cell receptor gene rearrangement. This patient is alive with disease at 7 years after presentation, so the presence of bone marrow involvement, if real, has had little clinical impact. Two additional patients were reported to have inguinal lymph node involvement, one of whom also had positive bone marrow. This latter case is the only patient classified as having Ann Arbor Stage IV disease. This 41-year old male was asymptomatic at presentation, and is untreated, being alive with disease at 1 year. Curiously, the remaining three patients said to have "biopsy-proven" involvement of lymph node or bone marrow were classified as stage IE at diagnosis. Presumably, the stated bone marrow or lymph node involvement occurred at some later point during the clinical course. More data are needed to understand the clinical and biological significance of this extraintestinal dissemination, including molecular data to confirm involvement.

A remaining issue is the optimal therapy for ITLPDGIT. Most of the data are anecdotal. A number of patients have been treated with a variety of chemotherapy regimens used in both B-cell and T-cell lymphomas. ${ }^{9}$ Most patients have failed to achieve any long-term benefit from conventional chemotherapy. The JAK-STAT pathway appears to be an attractive target, especially in patients with $\mathrm{CD}^{+}$disease, and in recent years there has been interest in the use of targeted agents for a variety of mature T-cell and NK-cell malignancies. ${ }^{24}$ Ruxolitinib is a JAK-inhibitor approved for use in myeloproliferative neoplasms, and has shown some activity in cutaneous T-cell lymphomas with activation of the JAK-STAT pathway. ${ }^{24}$ Other agents under evaluation for T-cell and NK-cell lymphomas include tofacitinib, pacritinib, and the histone deacetylase inhibitor, chidamide. The use of targeted agents in combination with either chemotherapy or immunotherapy may offer promise in the future.

\section{References}

1. Isaacson $\mathrm{P}$, Wright $\mathrm{D}$. Malignant histiocytosis of the intestine: its relationship to malabsorption and ulcerative jejeunitis. Hum Pathol. 1978:9(6):661-677.

2. Isaacson P, Spencer J, Connolly C, et al. Malignant histiocytosis of the intestine: a T-cell lymphoma. Lancet. 1985;2(8457):688-691.

3. Swerdlow SH, Campo E, Pileri SA, et al. The 2016 revision of the World Health Organization classification of lymphoid neoplasms. Blood. 2016;127:2375-90.

4. Carbonnel F, Lavergne A, Messing B, et al. Extensive small intestinal T-cell lymphoma of low-grade malignancy associated with a new chromosomal translocation. Cancer. 1994;73(4):1286-1291.

5. Egawa N, Fukayama M, Kawaguchi K, et al. Relapsing oral and colonic ulcers with monoclonal T-cell infiltration. A low grade mucosal T-lymphoproliferative disease of the digestive tract. Cancer. 1995;75(7):1728-1733.

6. Hirakawa K, Fuchigami T, Nakamura S, et al. Primary gastrointestinal T-cell lymphoma resembling multiple lymphomatous polyposis. Gastroenterology. 1996;111(3):778-782

7. Ranheim EA, Jones C, Zehnder JL, Warnke R, Yuen A Spontaneously relapsing clonal, mucosal cytotoxic T-cell lymphoproliferative disorder: case report and review of the literature. Am J Surg Pathol. 2000;24(2):296-301

8. Isomoto H, Maeda T, Akashi T, et al. Multiple lymphomatous polyposis of the colon originating from T-cells: a case report. Dig Liver Dis. 2004;36(3):218-221

9. Perry AM, Warnke RA, Hu Q, et al. Indolent T-cell lymphoproliferative disease of the gastrointestinal tract. Blood. 2013;122(22):35993606 .

10. Margolskee E, Jobanputra V, Lewis SK, Alobeid B, Green PH, Bhagat G. Indolent small intestinal CD4+ T-cell lymphoma is a distinct entity with unique biologic and clinical features. PLoS One. 2013;8:e68343.

11. Perry AM, Bailey NG, Bonnett M, Jaffe ES, Chan WC. Disease progression in a patient with indolent T-cell lymphoproliferative disease of the gastrointestinal tract. Int J Surg Pathol. 2019;27(1):102-107.

12. Soderquist CR, Patel N, Murty VV, et al. Genetic and phenotypic characterization of indolent T-cell lymphoproliferative disorders of the gastrointestinal tract. Haematologica. 2020;105(7):1895-1906.

13. Amador C, Greiner TC, Heavican TB, et al. Reproducing the molecular subclassification of peripheral T-cell lymphoma-NOS by immunohistochemistry. Blood. 2019;134(24):2159-2170.

14. Koskela HLM, Eldfors S, Ellonen P, et al. Somatic STAT3 mutations in large granular lymphocytic leukemia. $N$ Engl J Med. 2012;366(20):1905-1913.

15. Nicolae A, Xi L, Pittaluga S, et al. Frequent STAT5B mutations in $\gamma \delta$ hepatosplenic T-cell lymphomas. Leukemia. 2014;28 (11):2244-2248.

16. Nicolae A, Xi L, Pham TH, et al. Mutations in the JAK/STAT and RAS signaling pathways are common in intestinal $\mathrm{T}$-cell lymphomas. Leukemia. 2016;30(11):2245-2247

17. Roberti A, Dobay MP, Bisig B, et al. Type II enteropathy-associated T-cell lymphoma features a unique genomic profile with highly recurrent SETD2 alterations. Nat Commun. 2016;7:12602.

18. Chiarle R, Simmons WJ, Cai HY, et al. Stat3 is required for ALKmediated lymphomagenesis and provides a possible therapeutic target. Nat Med. 2005;11(6):623-629

19. Crescenzo R, Abate F, Lasorsa E, et al. Convergent mutations and kinase fusions lead to oncogenic STAT3 activation in anaplastic large cell lymphoma. Cancer Cell. 2015;27(4):516-532.

20. Blombery P, Thompson E, Jones K, et al. Whole exome sequencing reveals activating JAK1 and STAT3 mutations in breast-implant associated anaplastic large cell lymphoma. 2016;101(9):e387-e390.

21. Laurent C, Nicolae A, Laurent C, et al. Gene alterations in epigenetic modifiers and JAK-STAT signaling are frequent in breast implantassociated ALCL. Blood. 2020;135(5):360-370.

22. Xiao W, Gupta GK, Yao J, et al. Recurrent somatic JAK3 mutations in NK-cell enteropathy. Blood. 2019;134(12):986-991.

23. Sharma A, Oishi N, Boddicker RL, et al. Recurrent STAT3-JAK2 fusions in indolent T-cell lymphoproliferative disorder of the gastrointestinal tract. Blood. 2018;131(20):2262-2266.

24. Shouse G, Nikolaenko L. Targeting the JAK/STAT pathway in T cell lymphoproliferative disorders. Curr Hematol Malig Rep. 2019;14 (6):570-576. 